had a sensitivity of $48.8 \%(95 \% \mathrm{Cl} 39.7,57.9)$ and specificity of $97.4 \%(95 \% \mathrm{Cl}$ $84.9,99.9)$. A hypothetical sequential strategy of US followed by biopsy in the case of negative US had a sensitivity of $78.9 \%(95 \% \mathrm{Cl} 70.1,85.5)$ and specificity of $71.8 \%(95 \% \mathrm{Cl} 54.9,84.5)$, equivalent to a simultaneous testing strategy. Time on glucocorticoids did not significantly impact the results of US or biopsy. The only factor independently predictive of a positive US was male sex (OR 5.53, 95\% $\mathrm{Cl} 2.72$ to $11.22, \mathrm{p}<0.001)$. The only factor independently predictive of a positive biopsy was jaw claudication (OR $2.40,95 \% \mathrm{Cl} 1.11,5.21, \mathrm{p}=0.027$ ).

Table 1. Performance Characteristics of Ultrasound, Biopsy, and Combination Strategies

\begin{tabular}{lcccccc}
\hline Strategy & Sensitivity & Specificity & PPV & NPV & PLR & NLR \\
\hline Ultrasound alone & 52.8 & 71.8 & 85.6 & 32.6 & 1.87 & 0.66 \\
Biopsy alone & 48.8 & 97.4 & 98.0 & 37.6 & 19.02 & 0.53 \\
Sequential (Biopsy only if US positive) & 22.8 & 97.4 & 96.6 & 28.6 & 8.88 & 0.79 \\
Sequential (Biopsy only if ultrasound negative) & 78.9 & 71.8 & 89.8 & 51.9 & 2.80 & 0.29 \\
Simultaneous & 78.9 & 71.8 & 89.8 & 51.9 & 2.80 & 0.29 \\
Procedure, glucocorticoid duration & & & & & & \\
$\quad$ Ultrasound, all, $\mathrm{n}=162$ & 52.8 & 71.8 & 85.6 & 32.6 & 1.87 & 0.66 \\
$\quad$ Ultrasound, 0 days, $\mathrm{n}=80$ & 51.9 & 76.9 & 82.4 & 43.5 & 2.25 & 0.63 \\
$\quad$ Ultrasound, $>0 \leq 3$ days, $\mathrm{n}=27$ & 46.2 & 100 & 100 & 6.0 & Infinity & 0.54 \\
$\quad$ Ultrasound, $>3 \leq 7$ days, $\mathrm{n}=25$ & 60.0 & 40.0 & 80.0 & 20.0 & 1.00 & 1.00 \\
$\quad$ Ultrasound, $>7 \leq 14$ days, $\mathrm{n}=18$ & 64.3 & 50.0 & 81.8 & 28.6 & 1.29 & 0.71 \\
$\quad$ Ultrasound, $>14$ days, $\mathrm{n}=12$ & 44.4 & 100 & 100 & 37.5 & Infinity & 0.56 \\
Biopsy, all, $\mathrm{n}=162$ & 48.8 & 97.4 & 98.0 & 37.6 & 19.02 & 0.53 \\
Biopsy, 0 days, $\mathrm{n}=53$ & 46.9 & 100 & 100 & 55.3 & Infinity & 0.53 \\
Biopsy, $>0 \leq 3$ days, $\mathrm{n}=24$ & 66.7 & 83.3 & 92.3 & 45.5 & 4.00 & 0.40 \\
Biopsy, $>3 \leq 7$ days, $\mathrm{n}=38$ & 47.1 & 100 & 100 & 18.2 & Infinity & 0.53 \\
Biopsy, $>7 \leq 14$ days, $\mathrm{n}=29$ & 47.8 & 100 & 100 & 33.3 & Infinity & 0.52 \\
Biopsy, $>14$ days, $\mathrm{n}=18$ & 37.5 & 100 & 100 & 17.0 & Infinity & 0.63 \\
\hline
\end{tabular}

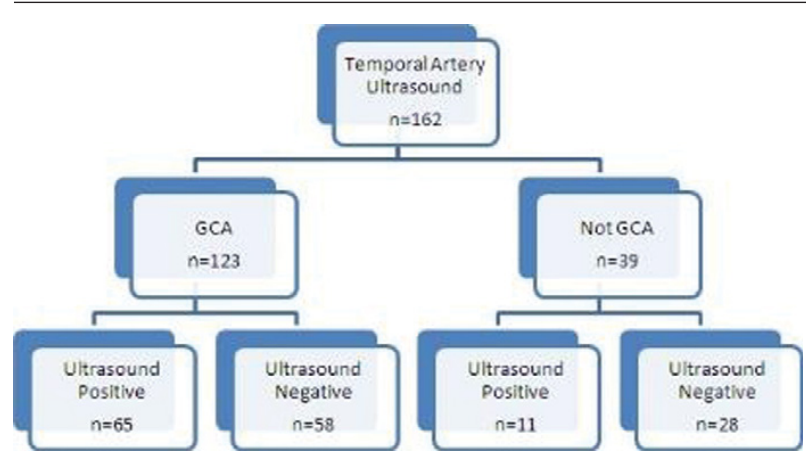

Conclusions: TA US is a useful tool in the diagnosis of GCA; however false positive tests occur in 7\% and thorough clinical assessment remains crucial. Prior glucocorticoid treatment has no clear impact on results.

Disclosure of Interest: None declared

DOI: 10.1136/annrheumdis-2017-eular.4629

\section{THU0313 INFERIOR AND SUPERIOR VENA CAVA THROMBOSIS IN BEHCET S DISEASE. MOROCCAN EXPERIENCE}

F.Z. Alaoui ${ }^{1}$, M. Moudatir ${ }^{2} .{ }^{1}$ Internal medicine; ${ }^{2} 12$ rue la saone, Polo, University hospital ibn rochd, Casablanca, Morocco

Background: Behcet's disease (BD) is a systemic disorder with a vascular tropism where the vessels might be affected. Venous thrombosis is the most common vascular complication. Among its locations, vena cava thrombosis (VCT) are rare but can be life-threatening.

The purpose of this work is to specify the frequency of VCT in the course of Behcet's disease in morocco and to analyse epidemiological, clinical and therapeutic modalities.

Objectives: This retrospective study was conduced in the internal medicine department of the University Hospital IbnRochd of Casablanca, over a period of thirty-five years between 1980 and 2016 .

Methods: Where included 1618 cases of Behcet's disease, all diagnosed in our service and meeting the diagnosis criteria as defined by the international study group (ISG) for Behcet's disease.

Results: 52 patients with VCT -47 men and 4 women - were gathered during this period, representing a rate of $3.30 \%$ of 1572 cases, with a mean age of 35 years (ranges 17-54).

The diagnosis of VCT and BD was concomitant in 10 cases and occurred during the course of the disease in 42 cases after an average of 6 years of evolution. Among the localization. Inferior VCT is the most frequent localization ( 32 patients, including 15 cases of Budd- Chiari syndrome). The superior VCT was reported in 24 patients, whereas 5 patients had both a superior and inferior VCT.Vena cava thrombosis was associated with deep venous thrombosis (DVT) of the lower limbs in 24 cases and with an aneurysm in 7 cases (pulmonary artery: 4 cases, femoral artery: 2 cases, abdominal aorta; 1 case).

Regarding the therapeutic modalities, 41 patients were under anti-coagulant treatment, 45 patients received corticosteroids and 51 of the patients were under immunosuppressive agents (cyclophosphamide,azathioprine).
The evolution was significantly improved after the introduction of the immunosuppressive therapy, which were firstly initiated in 2006.

Conclusions: Vena cava thrombosis in the context of Behcet's disease is a very serious pathology threatening the patient's vital and functional prognosis.

Preventive measures, early diagnosis and effective treatment are the keys to a successful management of such complications' risks.

Disclosure of Interest: None declared

DOI: 10.1136/annrheumdis-2017-eular.6965

\section{THU0314 RADIOLOGIC ACTIVITY IS THE MAJOR DETERMINANT FOR PHYSICIANS WHILE DECIDING ACTIVE DISEASE IN TAKAYASU ARTERITIS}

G. Kenar ${ }^{1}$, P. Cetin ${ }^{2}$, H. Yarkan ${ }^{1}$, B. Zengin ${ }^{1}$, G. Can ${ }^{1}$, M. Birlik ${ }^{1}$, F. Onen ${ }^{1}$.

${ }^{1}$ Rheumatology, Dokuz Eylul University School of Medicine, Izmir;

${ }^{2}$ Rheumatology, Dumlupınar University, Kutahya, Turkey

Background: There are no valid follow-up parameters in the assessment of disease activity in Takayasu arteritis (TA).

Objectives: We investigated the impact of incorporation of vascular imaging into

ITAS in the assessment of disease activity in TA.

Methods: 52 patients who fulfilled the ACR criteria were included in the study. PGA, Kerr et al.'s criteria and ITAS2010/ITAS-A scores were evaluated in all patients in serial visits. All the patients were followed using 3-6 monthly Bmode/Doppler ultrasonography (USG) and 6-12 monthly magnetic resonance angiography (MRA).

Radiological activity (Rad) was defined based on the presence of any of the 3 parameters including new vessel involvement by any technique ( 5 points), increase in vessel wall thickness on USG ( 3 points) and vessel wall edema on MRA ( 3 points).Then we incorporated these scores with ITAS-A to obtain a composite disease activity index (ITAS2010-A-Rad) (Table 1). Active disease was defined as ITAS-A-Rad $>4$ points.

Results: Total 410 visits of 52 TA patients (mean age $50.7 \mathrm{yrs}, \mathrm{F}: 92.3 \%$, mean follow-up duration:6.4 $\pm 2.9 \mathrm{yrs}$ ) were evaluated. Radiological assessment was done in 359 visits (by USG in 271 and by MRA in 190). Patients were categorized as having active disease in 194 visits (47.4\%) according to PGA and 72 visits (17.5\%) according to Kerr et al. criteria. The agreement between them was fair $(66 \%, \kappa$ : 0.29). Radiological activity was determined in 105 out of 359 visits (29.2\%). The total agreement between radiological activity and Kerr at al. criteria was $83 \%$ ( $\kappa$ : 0.58). It was found to be $76 \%$ (к: 0.52 ) between radiological activity and PGA.

Mean ITAS-A-Rad scores were found to be significantly higher in visits with active disease compared to visits with inactive disease according to both PGA and Kerr et al. criteria (Table 2). The ITAS-A-Rad was significantly correlated with all the other activity parameters including ITAS2010, ITAS-A, and APRs.

There were 43 visits with new vessel involvement by any radiologic technique; all visits included patients with active disease based on both PGA and Kerr et al. criteria. Whereas in $50 \%$ of these visits, patients had normal CRP, and \%49 had normal ESR.

The agreement between ITAS2010 and PGA was fair (69\%, к: 0.38). When APR was added (ITAS-A), it did not improve $(68 \%, \kappa: 0.34)$. But the agreement between

Table 1. The definition of ITAS-A-Rad Score

\begin{tabular}{|c|c|c|c|c|}
\hline Clinical & ITAS2010 & & & 0 \\
\hline \multirow[t]{2}{*}{ Laboratory } & APR & ESR & $\begin{array}{c}0 \text { for ESR }<20 \\
1 \text { for } 21-39 \\
2 \text { for } 40-59 \\
3 \text { for }>60 \mathrm{~mm} / \mathrm{h}\end{array}$ & \\
\hline & & CRP & $\begin{array}{c}0 \text { for } C R P \leq 5 \\
1 \text { for } 6-10 \\
2 \text { for } 11-20 \\
3 \text { for }>20 \mathrm{mg} / 1\end{array}$ & 0,0 \\
\hline \multirow[t]{3}{*}{ Radiology } & $\begin{array}{l}\text { Radiological } \\
\text { activity }\end{array}$ & $\begin{array}{l}\text { New vessel } \\
\text { involvement with any } \\
\text { radiological method }\end{array}$ & & \\
\hline & & B-mode Doppler USG & Progression on vessel wall thickness & 3 \\
\hline & ITAS-A-RAD & MRA & Presence of vessel wall edema & 3 \\
\hline
\end{tabular}

$\frac{\text { Score }}{\text { ITAS-A-Rad Score }>4->\text { Activity. }}$
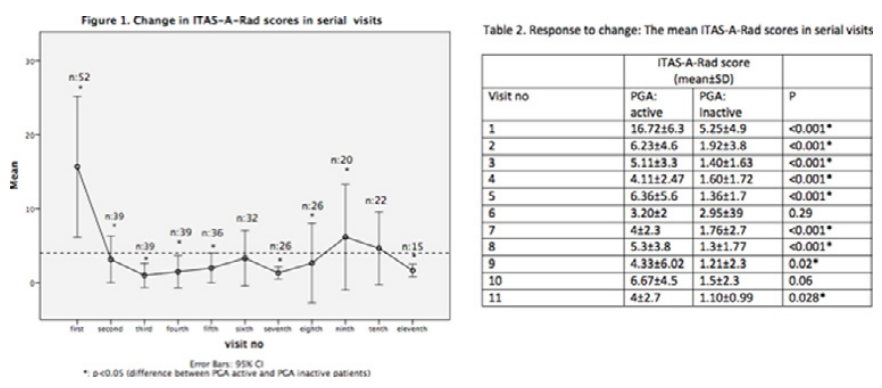